\title{
Article \\ Problems of Hydrogen Doping in the Methane Fermentation Process and of Energetic Use of the Gas Mixture
}

\author{
Marcin Herkowiak *, Barbara Łaska-Zieja, Andrzej Myczko and Edyta Wrzesińska-Jędrusiak
}

check for

updates

Citation: Herkowiak, M.;

Łaska-Zieja, B.; Myczko, A.;

Wrzesińska-Jędrusiak, E. Problems of

Hydrogen Doping in the Methane

Fermentation Process and of

Energetic Use of the Gas Mixture.

Appl. Sci. 2021, 11, 6374. https://

doi.org/10.3390/app11146374

Academic Editors:

Agnieszka Pilarska and

Krzysztof Pilarski

Received: 7 June 2021

Accepted: 5 July 2021

Published: 9 July 2021

Publisher's Note: MDPI stays neutral with regard to jurisdictional claims in published maps and institutional affiliations.

Copyright: (c) 2021 by the authors. Licensee MDPI, Basel, Switzerland. This article is an open access article distributed under the terms and conditions of the Creative Commons Attribution (CC BY) license (https:// creativecommons.org/licenses/by/ $4.0 /)$.
Institute of Technology and Life Sciences-National Research Institute, Falenty, Al. Hrabska 3, 05-090 Raszyn, Poland; b.laska@itp.edu.pl (B.Ł.-Z.); a.myczko@itp.edu.pl (A.M.); e.jedrusiak@itp.edu.pl (E.W.-J.) * Correspondence: m.herkowiak@itp.edu.pl

\begin{abstract}
This article discusses the technology for doping hydrogen into the fermenter to increase methane production and the amount of energy in the mixture. Hydrogen doping is anticipated to enable more carbon to be applied to produce methane. Hydrogen is proposed to be produced by using excess electricity from, for example, off-peak electricity hours at night. The possibilities of using a mixture of hydrogen and biogas for combustion in boilers and internal combustion engines have been determined. It has been proven that the volumetric addition of hydrogen reduces the heat of combustion of the mixture. Problems arising from hydrogen doping during the methane fermentation process have been identified.
\end{abstract}

Keywords: energy surplus; hydrogen; biogas; methane fermentation; doping

\section{Introduction}

The Polish market is abundant in large quantities of out-of-date food and has a large potential for agricultural biomass that can be a raw material for biogas production. Various sources [1,2] suggest that this quantity may range from 12 to 14 billion cubic meters, including 7 to 8 billion cubic meters of biomethane. Meanwhile, in Poland, only 114 biogas plants are registered in the National Support Centre for Agriculture [3]. It can therefore be concluded that a theoretical potential for biogas production is unused. In the meantime, in agriculture, due to the need to sanitize livestock manure [4], biogas production will require enormous investment, despite the fact that biogas electricity generation plants are several times more expensive than comparably powerful photovoltaic plants. However, the necessity of investing in biogas production does not only result from the sanitization of livestock manure but also from technical limitations of our power grids that so far occur in the grid connection of photovoltaic plants [5]. This problem is expected to exacerbate in the coming years, as it requires enormous investments to be solved. It is more complex than that presented in media reports. Biomethane production is the future in Poland. Purification to network gas parameters is usually considered an alternative to various forms of biogas upgrading. Then, the methane content of biogas is improved but with some loss of methane and carbon dioxide. Biogas is purified using various methods based on, e.g., adsorption, including pressure swing adsorption (PSA), water, chemical and organic scrubber methods, as well as membrane techniques. New developments in biogas treatment technologies such as cryogenic separation and in situ methane enrichment are also available. The lowest methane losses are associated with chemical scrubbers $(<0.1 \%)$, while the greatest losses of up to $8 \%$ are observed in the in situ method. The most frequently mentioned advantage of biomethane over biogas is that biomethane can be considered a direct energy carrier in the gas network or as a fuel for transport [6,7].

However, only the first such plants are constructed, and their impact on the economy will depend on the development of new plants and modernization of existing ones. In investment projects, however, a decisive factor is the economic calculation, notably with respect to modernization, as most cogeneration systems in our biogas plants are not yet 
depreciated. Further, economics will determine the extent and pace of investment in hydrogen production plants as even more than $50 \mathrm{kWh}$ must be used to produce $39.72 \mathrm{kWh}$ of energy contained in $1 \mathrm{~kg}$ of hydrogen, and an additional $15 \mathrm{kWh}$ if it is liquefied. Although Poland ranks third in terms of total hydrogen production capacity, its commercial hydrogen production capacity is small. Most hydrogen, not only in Poland, is obtainable either from surpluses in chemical plants and refineries or is a waste product [8,9]. At present, hydrogen production in Europe is principally based on fossil sources, primarily natural gas by means of steam reforming. This technology produces $90.6 \%$ of the hydrogen in Europe. The second method, in terms of production volume, is hydrogen as a by-product of chemical processes. This production currently provides $7.1 \%$ of hydrogen. The next process is electrolysis based on electricity from various sources, including fossil fuel power plants. This process is responsible for $1.6 \%$ of the hydrogen in Europe. This is followed by $0.7 \%$ of hydrogen produced by low-emission CCS steam reforming [10]. Only $0.1 \%$ of hydrogen is produced from renewable sources [11].

Therefore, notably in the case of off-grid and local biogas utilization, more attention should be paid to technologies that improve current biogas production and upgrading and utilizing techniques. In the interim period until the so-called Green Deal, the existing infrastructure and a new and improved product based on the already proven technology elements will be employed.

Numerous authors have published data on the energy in hydrogen. The heat of combustion of hydrogen is $143 \mathrm{MJ} \cdot \mathrm{kg}^{-1}$, which means $39.72 \mathrm{kWh} \cdot \mathrm{kg}^{-1}$ [12], whereas Wiacek [13] demonstrates a calorific value of hydrogen of $33.3 \mathrm{kWh} \cdot \mathrm{kg}^{-1}$. The undoubted disadvantage of hydrogen is its low energy density. Under atmospheric conditions, the heat of combustion of hydrogen per unit volume is $10.79 \mathrm{MJ} / \mathrm{m}^{3}$ for hydrogen gas. When hydrogen is liquefied, its density improves, and the heat of combustion amounts to $1010 \mathrm{MJ} \cdot \mathrm{kg}^{-1}$. Unfortunately, hydrogen liquefaction is a highly energy-intensive process and requires special apparatus.

Hydrogen has the highest energy value per unit weight of fuel $\left(120 \mathrm{MJ} \cdot \mathrm{kg}^{-1}\right)$ In terms of its weight, hydrogen has almost three times the energy content of, for example, petrol $\left(44.5 \mathrm{MJ} \cdot \mathrm{kg}^{-1}\right)$ and methane $\left(50.0 \mathrm{MJ} \cdot \mathrm{kg}^{-1}\right)$. However, in volume terms, the situation is reversed. The heat of combustion of liquid hydrogen relative to volume is $8960 \mathrm{MJ} \cdot \mathrm{m}^{-3}$, petrol $31,170 \mathrm{MJ} \cdot \mathrm{m}^{-3}$ and methane $21,250 \mathrm{MJ} \cdot \mathrm{m}^{-3}$. The low density of hydrogen, about $0.08 \mathrm{~kg} \cdot \mathrm{m}^{-3}$ results in storage problems, particularly in automotive applications $[14,15]$.

In research conducted by Porpatham et al. [16], 5\%, 10\%, and 15\% of hydrogen energy was added to biogas and tested in a spark ignition engine at a constant speed and at different equivalence ratios to analyze its impact on performance, emissions, and combustion. Hydrogen significantly increased the rate of combustion and raised the limit for the use of the biogas mixture. The thermal efficiency and braking power improved. However, the addition of over $15 \%$ of hydrogen, required an ignition delay to control knocking combustion and did not improve biogas properties at high equivalence ratios. A significant reduction in hydrocarbon levels in exhaust fumes was observed. Furthermore, nitrogen oxide emissions did not increase due to the delayed ignition and the presence of carbon dioxide. Peak pressures and heat release rates were observed to be lower when hydrogen was added as the ignition time was delayed to avoid knocking. The research concluded that the addition of $10 \%$ of hydrogen to biogas was the most favorable [16].

As for the use of hydrogen for transport, it can be stored at a pressure of $700 \mathrm{bar}$. Such high pressures are necessary due to the low energy density of hydrogen. Meanwhile, methane tanks presently used in CNG systems usually have a pressure of 200 bar.

Other research on the hydrogen enrichment of biogas was conducted for a dual-fuel diesel engine. Parameters such as thermal efficiency, pollutant emissions, and combustion parameters were determined. Experiments were carried out on a stationary compression ignition (CI) engine coupled with a generator running in dual mode at a typical biogas composition of $60 \% \mathrm{CH}_{4}$ and $40 \% \mathrm{CO}_{2}$. The volume concentration of hydrogen varied from 5 to $20 \%$ of $\mathrm{H}_{2}$. The results showed an increase in peak pressure in the combustion chamber 
to 10.7 bar and diesel substitution levels of up to $80 \%$ under conditions of stable combustion without knocking. Further, thermal efficiency increased to $16 \%$ and carbon monoxide emissions decreased to $13 \%$ at full load and with the addition of $20 \%$ hydrogen [17].

Jaworski et al. [18] conducted research on the injection of hydrogen additive into the gas network and the impact of this additive on gas system components. As a result of the experiments, two levels of acceptable hydrogen content were determined: $10 \%$ and $8 \%$. The first level resulted from the acceptable method of calculating the compressibility factor, whereas the second one pertained to the explosion safety of measuring equipment intended for use in explosive atmospheres.

The objective of research and calculations is to identify problems and methods to increase the methane content and optimize the calorific value of the gas produced by doping hydrogen in different phases of the biomass methane fermentation process.

The assessment conducted on the basis of the available literature concludes that a solution is needed to generate enriched biogas with parameters that enable it to be used for various purposes related to energy management in rural areas. This process should be carried out at different stages of its production and use. It is assumed that this could be achieved by enriching the fermentation mixture with hydrogen to reduce the amount of carbon dioxide in biogas and increase the amount of methane. It is also assumed that an excess amount of hydrogen would be fed, but in such a quantity that the heat of combustion of the gas mixture obtained would not be reduced too much. This amount should depend on the purpose of gas and the method of its further use, e.g., for combustion in a boiler, and on doping of network gas into such enriched biogas for use in local networks, e.g., energy cooperatives.

The biogas with methane content ranging from 50 to $60 \%$ that is produced to date is not suitable, for example, for powering agricultural tractors. As shown by previous research undertaken at our institute [19] on the use of biogas as a fuel for agricultural tractors, the decrease in effective power was up to $39 \%$, depending on the content of methane in the biogas. The object of research was a tractor, S-4003, diesel, 4-cylinder engine with a displacement of $3121 \mathrm{~cm}^{3}$ and a rated power of $38.2 \mathrm{~kW}$ at $2200 \mathrm{rpm}^{-1}$. In dynamometer tests, a maximum effective Ne power of $14.97 \mathrm{~kW}$ was obtained at $1400 \mathrm{rpm}^{-1}$, and a specific fuel consumption of $321.7 \mathrm{~g} . \mathrm{kWh}^{-1}$. The addition of hydrogen to the fermenter chamber during the methane fermentation of biomass, on the other hand, makes it possible to increase the energy stored in biogas while reducing the content of carbon dioxide in the mixture. Therefore, it is necessary to develop a technology that enables biogas producers to improve the environmental performance of their technology, without the need for costly upgrading of biogas to network gas parameters, to obtain fuel for different purposes from surplus energy produced in various RES systems [20] and from biogas not used for cogeneration. Such technology will be particularly useful following the European Commission's plan to impose a ban on flaring biogas and releasing it into the atmosphere. Then, after appropriate compression, the excess biogas will be stored as a mixture suitable for energy use. Therefore, notably in the case of off-grid and local biogas utilization, more attention should be paid to technologies that improve current biogas production, upgrading, and utilization techniques. In the interim period until the so-called Green Deal, the existing infrastructure and a new and improved product based on the already proven technology elements will be employed.

\section{Materials and Methods}

\subsection{Hybrid Pump to Mix Fermenter Contents Using Biogas}

The research was conducted with the use of two devices: a hybrid pump for lifting a liquid with added solids, using a working medium such as gas or air, and a fermentation tank for disposing of liquid biomass with added solids by methane fermentation. The pump design was adapted to the shape of vertical fermenter. If a fermenter of a different shape is employed, the pump should be structurally modified. The fermentation tank prepared for research comprises an in-built hybrid pump that operates as a mammoth, geyser, or hybrid 
pump, depending on process requirements. The automatic control system can switch the operation into geyser mode or to a hybrid system. The times of each mode can be adjusted as required. In the pump-mixing system, biogas is directly collected above the surface of fermenting biomass and distributed into the fermenter contents. The pumped stream with a specific kinetic energy comprises biomass as fermenter contents and biogas as a working medium. The biogas supply line can be equipped with a line supplying hydrogen directly from the hydrolyser. The working medium that is part of the stream may have three forms: a substantial gas bubble, fine micro-bubbles, or both at the same time. The pumped stream saturates biomass with fresh biogas and homogenizes the composition and temperature of biomass throughout the fermenter volume. This is done by releasing a substantial gas bubble from the pump baffle assembly, which, flowing through the fermenting biomass bed, detaches the over-expanded microbial colonies and distributes them throughout the fermenter contents. This bubble, after passing through the biological bed, moves through the upper biomass fractions, mixes them, and finally rapidly agitates (shakes) the upper layer and the substrate surface, which results in a faster release of biogas.

As it goes through the entire system, the bubble pumps substantial amounts of biomass upwards. The fermenting biomass is saturated with fresh biogas or biogas with added hydrogen primarily through the operation of a diffuser that generates a cloud of fine gas bubbles. The efficiency of saturation of the entire biomass volume with gas is affected by the size of bubbles that are generated by the diffuser and rise slowly upwards, and consequently saturate and slowly mix the fermenting biomass. The diffuser is mounted at the bottom of the upper pump baffle, hence the cloud of gas bubbles generated is also transported to farther biomass fractions by periodically releasing the gas bubble from the vertical baffle assembly. When doping hydrogen into biogas, both gases are thoroughly mixed in chambers formed by vertical baffles, even before their use for mixing.

The gas-flow generation pump has a separate power supply for both functional parts, which means that the geyser section and the diffuser (or diffusers 1-2 and more) are separately powered, which enables the pump to operate in three variants: operation of geyser section, operation of diffuser-mammoth unit, and simultaneous operation of both sections. The choice of operation variant depends on the technological process requirements.

In this study, a functional pump model was constructed, tests were carried out, technical documentation of the biogas fermenter with an in-built pump was produced, a prototype integrated into a standard layout of a biogas plant utilizing pig slurry on a farm was developed, and functional tests of the entire biogas plant were carried out. A schematic diagram of the pump in Figures 1 and 2 shows a view of the model used to test the functionality and validity of the previous solutions (left) and a view of the design of the pump integrated into the digester (right). Figure 3 shows a general view of the pilot plant used to test the effect of hybrid pump mixing on methane yield increase. 


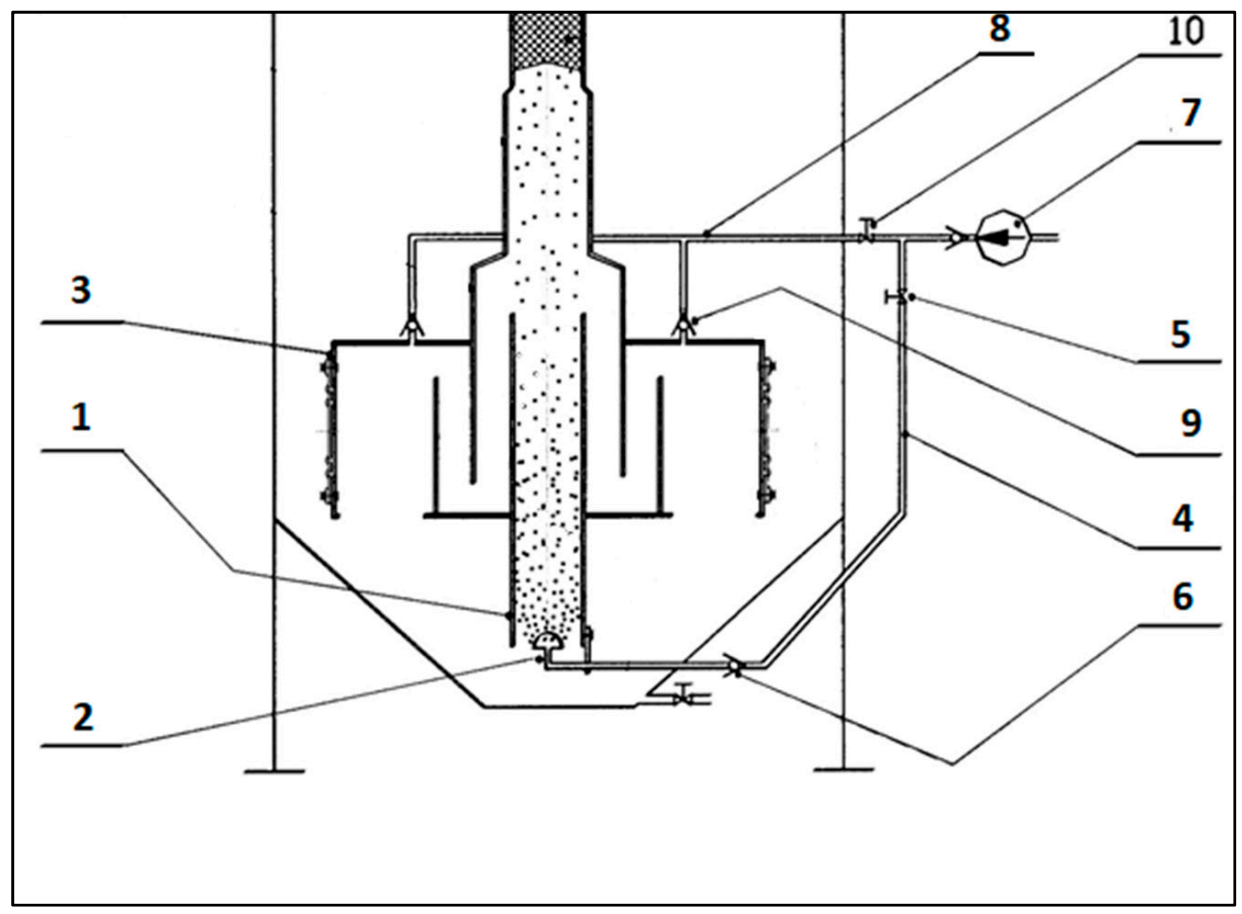

Figure 1. Diagram of the hybrid pump: 1-suction pipe, 2-diffuser, 3-working medium tanks closed from the top, 4-pipe, 5-control valve, 6-check valve, 7-compressor, 8-piping, 9—check valves, 10 - control valve with compressor.
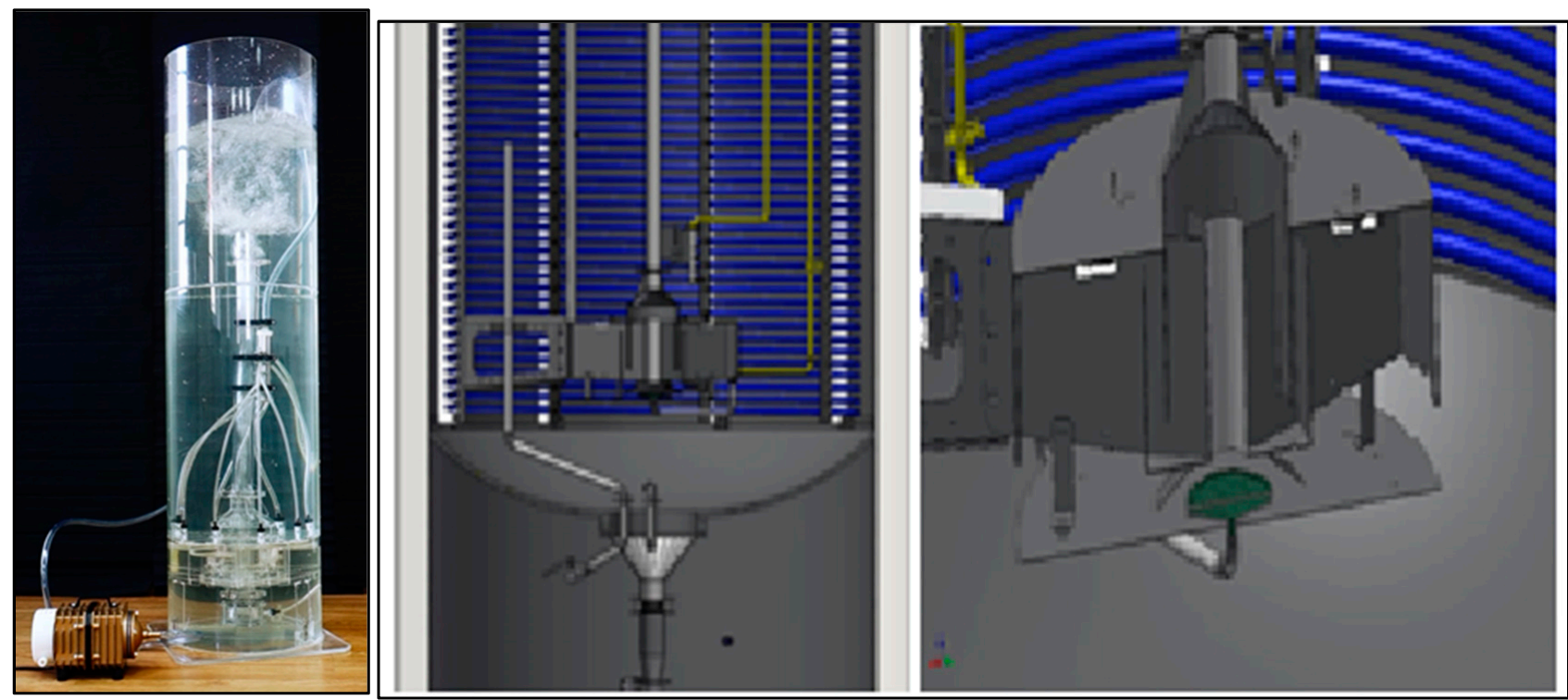

Figure 2. Hybrid pump: model (left) and design of the hybrid pump applied in the fermenter (middle and right) ([Source: image-ZOZE collection, Figure Mega-Bełżyce]). 


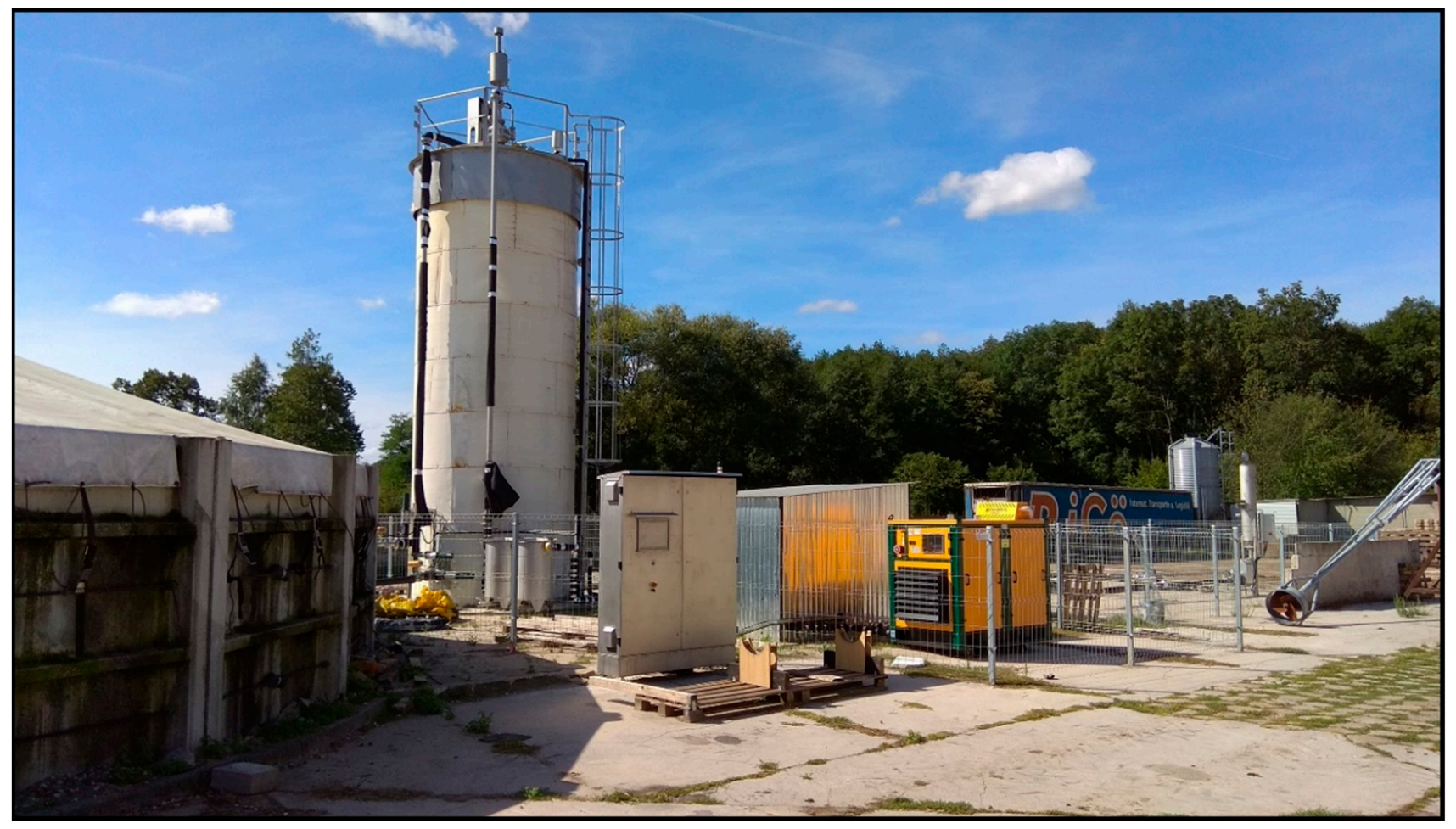

Figure 3. View of the biogas plant with a fermenter equipped with a hybrid pump.

\subsection{Application of a Hybrid Pump for Hydrogen Doping into Biogas during Methane Fermentation}

Figure 4 shows a schematic of the hydrogen production and utilization technology in combination with a biogas plant equipped with an innovative hybrid pump mixing system. This plant enables the mixing of fermenter contents using biogas as the working medium. In this technology, hydrogen is to be produced by electrolysis for which surplus electricity will be used. The surplus electricity is due to the reduced demand for energy generated during off-peak energy hours at night. These surpluses can also result from other reasons, where energy cannot be fed directly into the grid, e.g., due to technical constraints. This can be the case for renewable energy sources such as photovoltaics or wind turbines, among others, where the production of electricity is not constant over time and depends on weather factors or solar irradiation. The hydrogen produced by the process can be blended with biogas to improve combustion performance in conventional systems such as internal combustion engines or gas boilers. It is also assumed that hydrogen is dosed into the digester to improve methane yield by combining hydrogen with carbon during methane fermentation. The mixture of hydrogen and biogas can be compressed for distribution or use in transportation. 


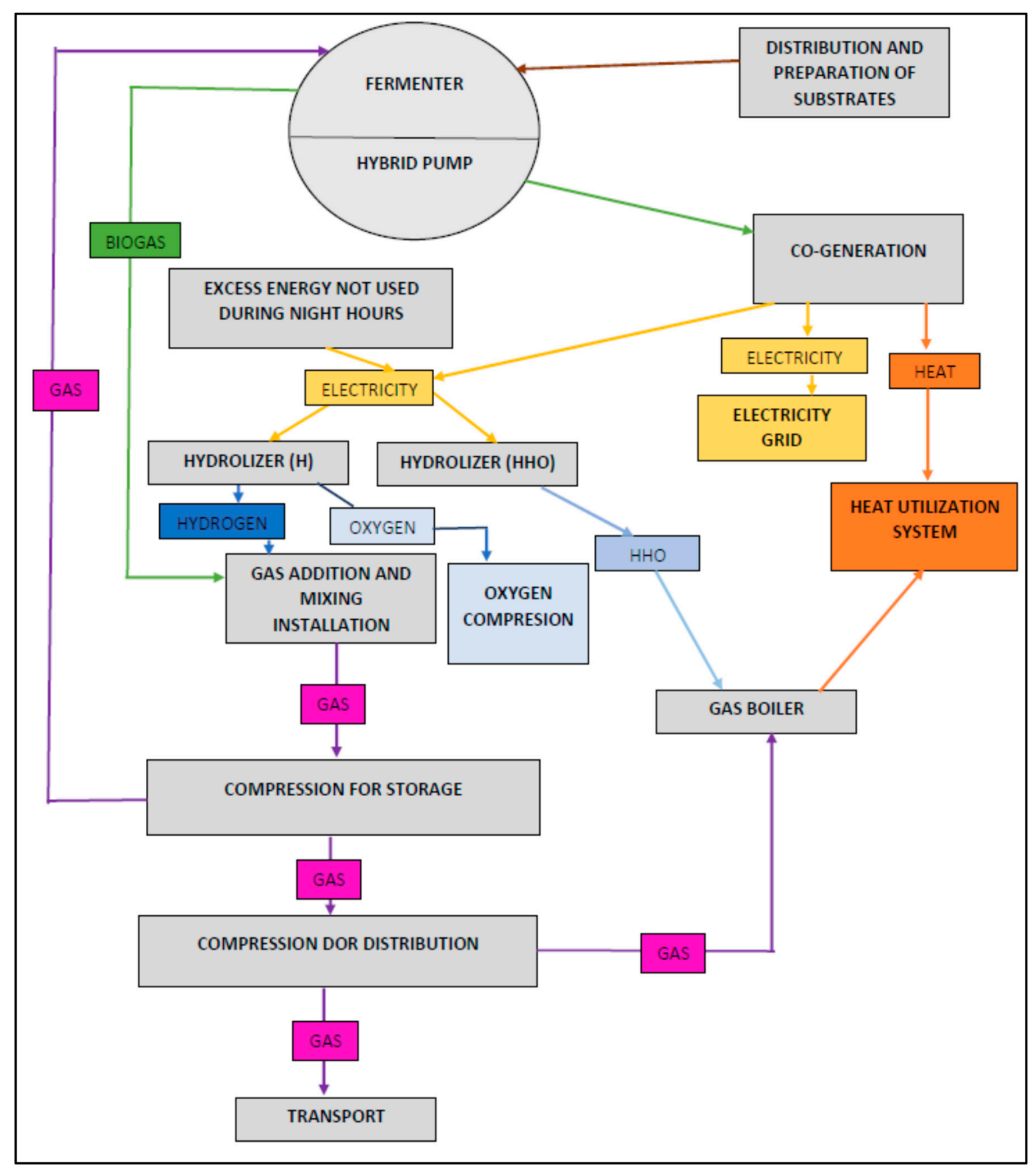

Figure 4. Gas and energy cycle scheme.

For the analyzed biogas plant equipped with the hybrid pump mixing technology, research was carried out on the possibility of increasing the methane content using the innovative mixing method. For this purpose, the plant's own measuring and control apparatuses were employed to determine the content of methane and carbon dioxide in biogas.

For the technology discussed above, changes in energy density were simulated for the mixture of biogas and hydrogen, depending on their proportion in the mixture.

The energy balance was calculated for selected technology stages concerning hydrogen production, its doping into hydrogen, and compression for storage and distribution purposes. The calculations were based on literature data on the energy intensity of hydrogen and biogas compression systems. The calculations analyzed various variants of hydrogen content in biogas, depending on the intended use of the gas mixture. As noted 
above, the research conducted by Porpatham et al. [16] proved that a hydrogen addition of $10 \%$ was the most favorable for powering the engine using the mixture of biogas and hydrogen. On the other hand, according to DOE [21], the use of hydrogen at a pressure of $700 \mathrm{bar}$ is the most favorable for transport. However, methane tanks presently used in CNG systems usually have a pressure of 200 bar. Therefore, it was assumed that the compression up to 200 bar would be analyzed for the gas mixture. In contrast, the $10 \%$ hydrogen content was adopted for the use of the gas mixture to power internal combustion engines as this content is the most favorable [16]. On the other hand, $8 \%$ was used for the use of gas in boilers due to the safety of gas fittings [18].

\section{Results}

\subsection{Biogas Composition}

Figure 5 shows the methane content in biogas produced in the fermenter equipped with a hybrid pump for lifting a liquid with added solids. The hydraulic retention time was nine days. The methane content in the composition of the analyzed biogas ranged from 57 to $72 \%$. On the fifth day after starting the pump, which used biogas as a mixing medium collected directly from above the surface of the fermenting biomass, an initial decrease and a subsequent significant increase in $\mathrm{CH}_{4}$ to over $70 \%$ were observed. As the methane content in the biogas increased, a decrease in $\mathrm{CO}_{2}$ was noted.

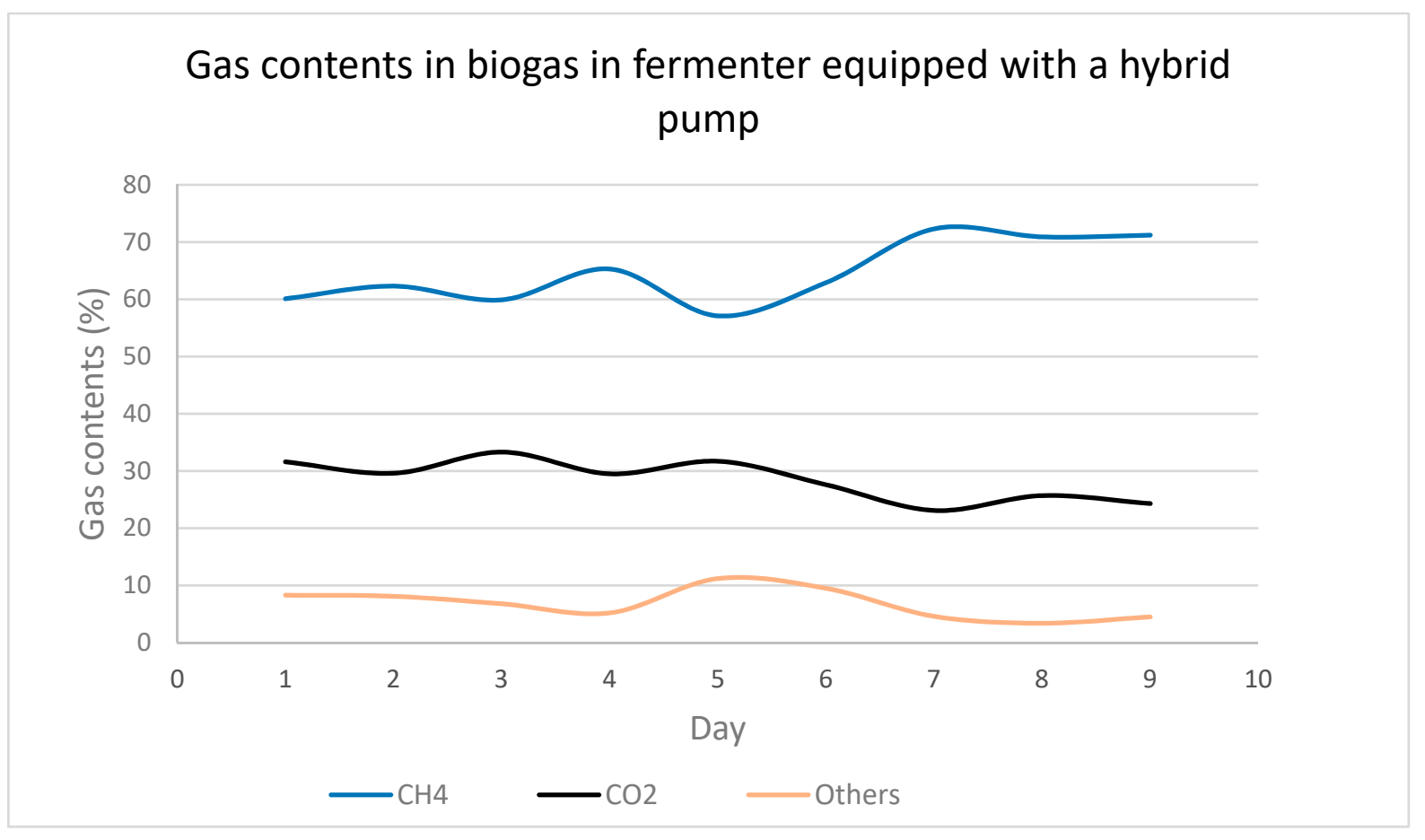

Figure 5. Increase in methane content in biogas produced in a fermenter with a hybrid pump after starting the fermenter.

\subsection{Parameters of the Mixture Biogas and Hydrogen}

The parameters of the mixture of biogas and hydrogen were simulated to determine its applicability for energy storage and generation purposes.

\subsubsection{Heat of Combustion of the Gas Mixture}

The calculations shown in Figure 6 were carried out to illustrate the changes in the heat of combustion of the mixture of biogas and hydrogen with a greater volume proportion of hydrogen. The heat of combustion of the mixture of biogas and hydrogen significantly changes as the quantities of individual gases change. Due to the low energy density of hydrogen, the heat of combustion of the mixture decreases as the volume of this gas in 
the mixture increases. Therefore, for storage the gas mixture should be compressed to compensate for the lower energy density.

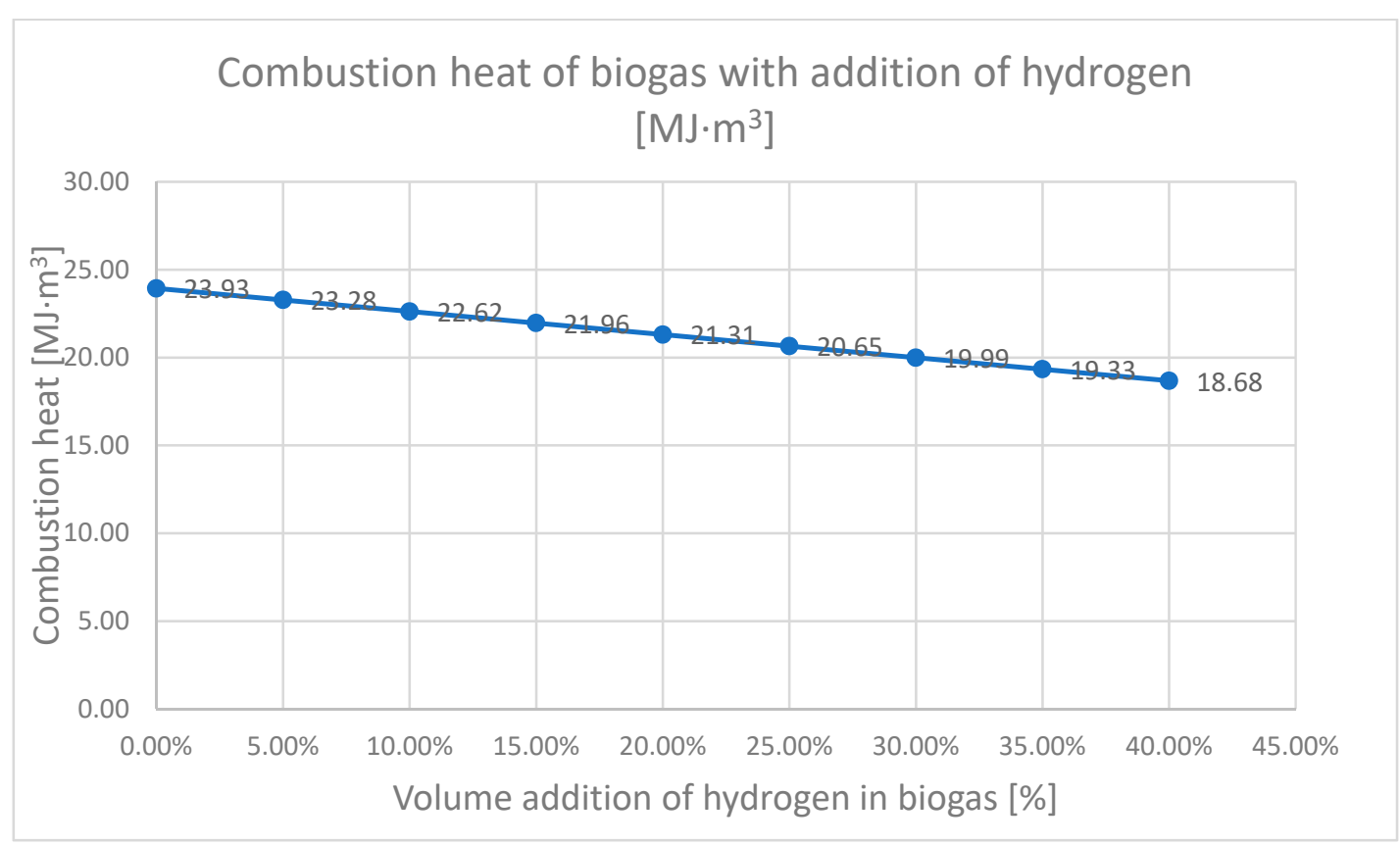

Figure 6. Change in the heat of combustion of the mixture of biogas and hydrogen with a higher volume content of hydrogen.

On the other hand, when referring to the heat of combustion of the mixture of biogas and hydrogen to the mass unit, the results obtained do not include the impact of the energy density of these gases, hence a small mass addition of hydrogen leads to a very high increase in the heat of combustion (Figure 7). This results from the high heat of combustion of hydrogen of $120 \mathrm{MJ} \mathrm{kg}^{-1}$.

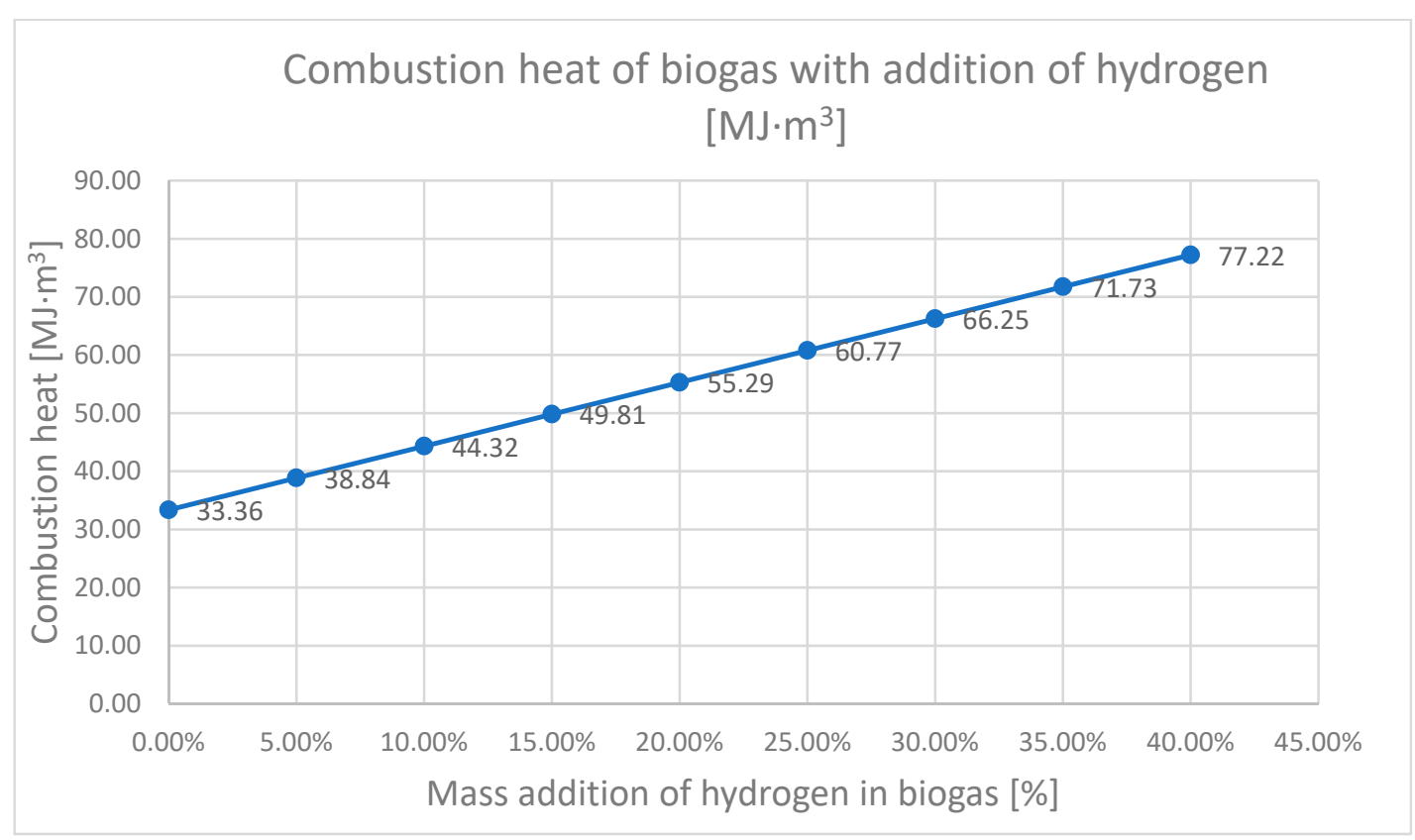

Figure 7. Change in the heat of combustion of the mixture of biogas and hydrogen with a higher mass content of hydrogen (dependence of the heat of combustion on the hydrogen content of biogas). 


\subsubsection{Change in Density and Volume of the Gas Mixture}

The graph in Figure 8 shows how a decrease in the density of the gas mixture leads to an increase in the mass proportion of hydrogen.

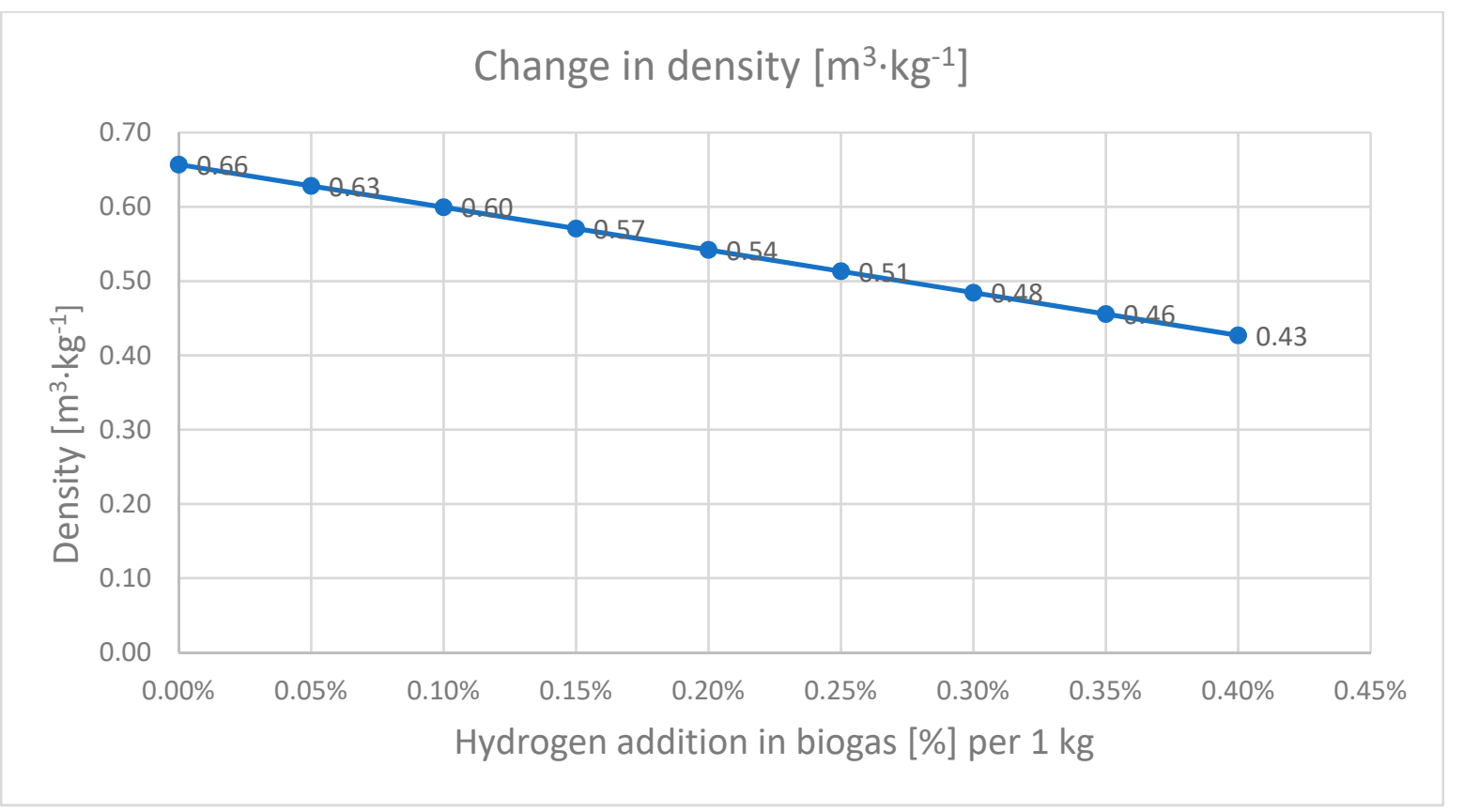

Figure 8. Change in gas density as a function of hydrogen mass content.

In view of the aforementioned difference in energy density, an increase in the mass proportion of hydrogen results in a significant increase in the volume of the gas mixture. Figure 9 shows changes in the volume of the gas mixture as a function of the percentage of hydrogen per $1 \mathrm{~kg}$ of the mixture. The graph shows that the gas mixture containing $40 \%$ hydrogen has almost four times the volume of biogas alone. Therefore, difficulties arise in storing this type of gas mixture, since the storage system needs to be equipped with fittings comprising compressors and tanks designed for storage under increased pressure.

The cost of producing hydrogen using renewable energy depends on the source of energy. The Hydrogen Europe report (2019) states that the cost of producing hydrogen by using photovoltaic farms ranges from 3.54 to 6.53 euro $/ \mathrm{kg}$, while using wind turbines it ranges from 4.72 to 6.41 euro $/ \mathrm{kg}$ [11].

\subsection{Energy Calculations}

On the basis of the literature review and previous calculations of the calorific value of the gas mixture, an approximate energy balance was conducted to demonstrate the cost-effectiveness of the technology. The criterion for the cost-effectiveness of the proposed technology was the amount of energy required for the use of gas (compression) and the amount of energy to be obtained from the use of the gas mixture. These calculations excluded the amount of energy required to produce hydrogen due to the use of excess energy to produce it. It was assessed, however, whether the amount of energy needed to use hydrogen did or did not exceed the amount of energy needed to produce it. 


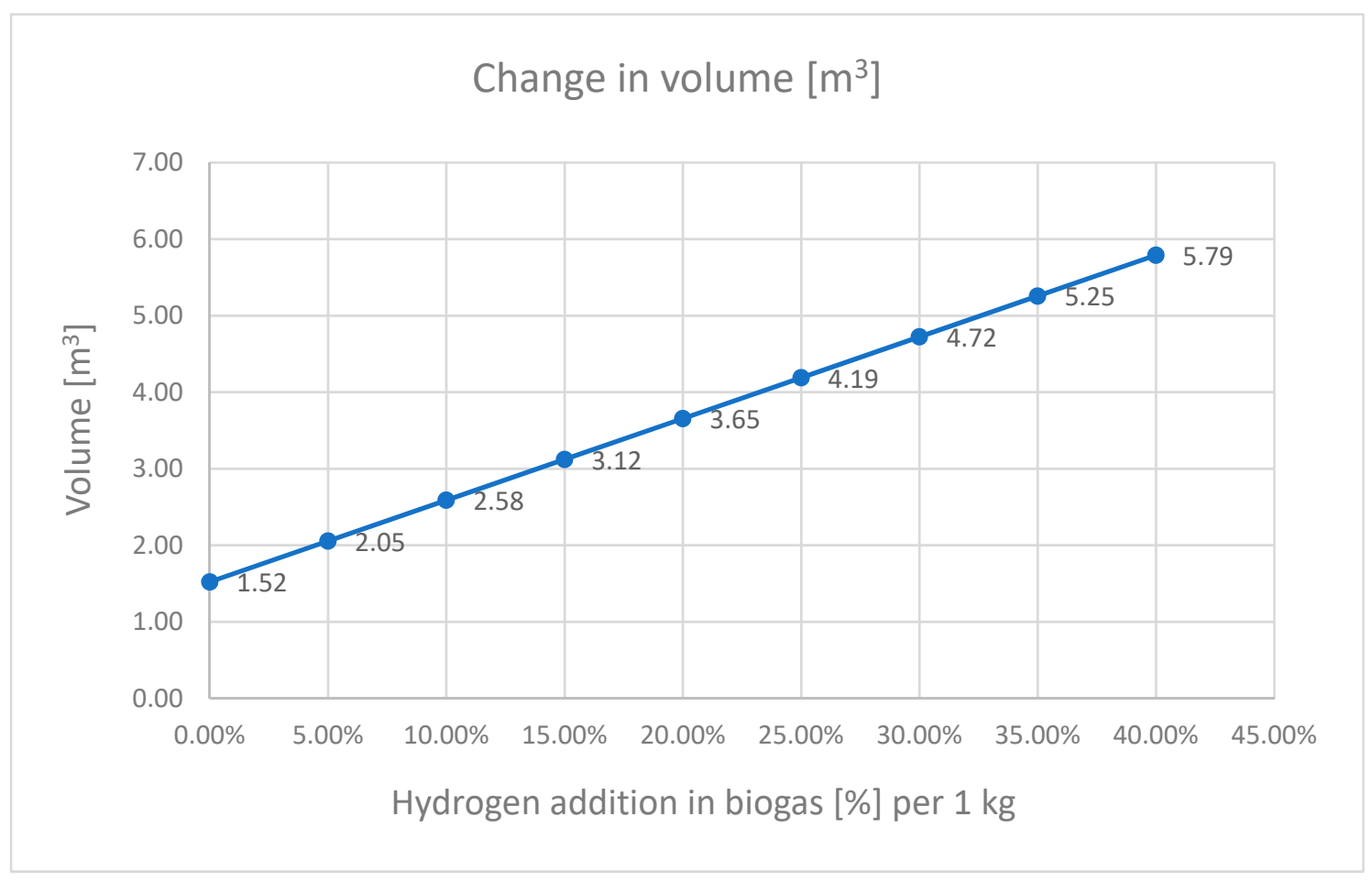

Figure 9. Change in gas volume as a function of hydrogen mass content.

\subsubsection{Combustion of the Mixture Injected into the Gas Network in Boilers}

A hydrogen content of $8 \%$ was assumed for calculations. This value allows such a mixture to be used safely in the gas network. As shown above, the heat of combustion of biogas with this hydrogen content is $23.93 \mathrm{MJ} \mathrm{m}^{-3}$. The calculations only included the energy obtained from the combustion of the mixture of biogas and hydrogen. The efficiency of the gas boiler was assumed to be $90 \%$.

$$
\mathrm{Et}=0.9 \times 22.88=20.59\left[\mathrm{MJ} \cdot \mathrm{m}^{-3}\right]
$$

The calculations resulted in $20.96 \mathrm{MJ}-\mathrm{m}^{-3}$ of heat from the combustion of the mixture of biogas and hydrogen. This amounts to $5.82 \mathrm{kWh} \mathrm{m}^{-3}$ of heat.

\subsubsection{Combustion in a Traction Engine}

A hydrogen content of $10 \%$ was assumed for calculations. The literature data prove that the combustion of a mixture with such proportions is the most favorable. The calculations mentioned above indicate that the heat of combustion of the mixture with such proportions equals $22.62 \mathrm{MJ} \cdot \mathrm{m}^{-3}$. The calculations involved the tractor, S-4003, diesel, 4cylinder engine with a displacement of $3121 \mathrm{~cm}^{3}$ and a rated power of $38.2 \mathrm{~kW}$ at $2200 \mathrm{rpm}$. The previous biogas-based research resulted in a speed of $1400 \mathrm{rpm}$ and a specific fuel consumption of 321.7 g.kWh ${ }^{-1}$. Due to the lower heat of combustion of the mixture of hydrogen and biogas, $339.31 \mathrm{~g}$ of fuel will be required per $1 \mathrm{kWh}$.

\section{Discussion}

This study recommends the use of excess electricity for hydrogen production. On the basis of the data available in the literature, the possible proportions of individual gases in the mixture were determined. According to the research described by Porpatham, E. et al. [16], 10\% hydrogen content was assumed to be used in the gas mixture. On the other hand, $8 \%$ hydrogen content was adopted for the gas injection into the network based on the data provided by Jaworski J. et al. [18] on the explosion safety of measuring devices 
intended for use in explosive atmospheres. These parameters should be further analyzed for specific engines, notably those used in agriculture.

This technology primarily assumes the use of excess amounts of energy generated at off-peak electricity hours at night, overproduced or coming from renewable energy sources. By using this source to produce hydrogen, it is possible to improve the environmental impact and energy balance of the process.

In addition, by introducing hydrogen into the fermenter during the methane fermentation process, an increased methane yield is expected as a result of combining hydrogen with carbon. The possibility of using more biomass carbon to produce methane would also have a positive environmental impact.

In view of the aforementioned difference in energy density, an increase in the mass proportion of hydrogen results in a significant increase in the volume of gas mixture. The gas mixture containing $40 \%$ of hydrogen has almost four times the volume of biogas alone. Therefore, difficulties arise in storing this type of gas mixture, since the storage system needs to be equipped with fittings comprising compressors and tanks designed storage under increased pressure. However, both methane and hydrogen must have a gaseous form in the mixture. This makes the gas mixture homogeneous and does not pose a challenge to the plants applied. For example, in automotive CNG systems, methane is stored at 210-250 bar. Consequently, a tank with a water volume of $42 \mathrm{~L}$ and a gas volume of $8.4 \mathrm{~m}^{3}$ can store $190 \mathrm{MJ}(52.78 \mathrm{kWh})$ of energy for a mixture containing $10 \%$ hydrogen. On the basis of the calculations of the density of the gas mixture and the fuel demand of the tractor engine, it can be calculated that the available amount of gas in such a tank would allow the tractor engine to produce $41.26 \mathrm{kWh}$.

Due to the low energy density of hydrogen, the mixture of hydrogen and biomethane needs to be compressed to higher pressures to compensate for the lower energy in the tanks than with biomethane alone. The authors claim that both gases must be in a gaseous state to ensure that the mixture is as homogeneous as possible. However, it is necessary to bear in mind that the benefit of using the mixture to power internal combustion engines is not only the use of excess electricity to produce hydrogen, but also the improvement of combustion parameters and reduction of emissions when burning this type of mixture [16].

\section{Conclusions}

The simulations of the gas mixture as a function of the percentage of individual gases have led to the following conclusions.

The heat of combustion of the mixture related to the volume and mass significantly differs due to the low energy density of hydrogen.

The heat of combustion of the mixture of biogas and hydrogen markedly changes as the quantities of individual gases change.

Due to the low energy density of hydrogen, the heat of combustion of the mixture decreases as the volume of this gas in the mixture increases. Therefore, for storage the gas mixture should be compressed to compensate for the lower energy density.

When comparing the heat of combustion of the mixture of biogas and hydrogen to the mass unit, the results obtained do not include the impact of the energy density of these gases, hence a small mass addition of hydrogen leads to a very high increase in the heat of combustion. This is a result of the high heat of combustion of hydrogen of $120 \mathrm{MJ} \mathrm{kg}^{-1}$.

The calculations show that the energy achievable through the use of the gas mixture is greater compared to the energy input required for its distribution.

Further research on the doping of hydrogen into the fermenter of a biogas plant during the ongoing biomass methane fermentation process should take into account to a greater extent the changes in the energy parameters of the gas mixture obtained, which should occur as a result of an increase in the methane content with a simultaneous decrease in the carbon dioxide content. In order to carry out in-depth research on this process, it is necessary to extend the plant on which the tests have been previously carried out, notably its automatic data recording system. At a later stage, we should also consider the 
benefits arising from the operation of the hybrid RES system that stores energy and has the opportunity of obtaining a guarantee of sale of energy from such a system, e.g., through an auction system. The benefits of using a plant with an energy storage system can also accrue to local energy plants, e.g., by reducing the use of grid energy and associated charges.

\section{Patents}

This section is not mandatory but may be added if there are patents resulting from the work reported in this manuscript.

Author Contributions: Conceptualization, M.H. and A.M.; Data curation, M.H. and B.E.-Z.; Formal analysis, M.H. and A.M.; Funding acquisition, A.M.; Investigation, M.H.; Methodology, M.H. and A.M.; Resources, M.H., B.Ł.-Z., A.M. and E.W.-J.; Supervision, M.H. and A.M.; Validation, M.H.; Visualization, M.H. and E.W.-J.; Writing—original draft, M.H., B.E.-Z., A.M. and E.W.-J; Writingreview \& editing, M.H., B.E.-Z., A.M. and E.W.-J. All authors have read and agreed to the published version of the manuscript.

Funding: The study is carried out under the project "Development of technology for rational management of bovine shavings from leather processing-MIZDRA 2.0" co-financed by the European Union from the European Regional Development Fund under the Operational Programme Intelligent Development 2014-2020; Priority IV: Improvement of the scientific and research potential; Activity 4.1 "Scientific Research and Development", Sub-activity 4.1.4 "Application projects" realized within the competition of the National Centre for Research and Development: POIR.04.01.04-00-0071/20.

Institutional Review Board Statement: Not applicable.

Informed Consent Statement: Not applicable.

Data Availability Statement: Not applicable.

Conflicts of Interest: The authors declare no conflict of interest.

\section{References}

1. Gradziuk, P. Potential and forecast for use of agricultural biogas in Poland. Rocz. Nauk. Stowarzyszenia Ekon. Rol. i Agrobiz. 2017, XIX, 64-70. [CrossRef]

2. Powałka, M.; Klepacka, A.; Skudlarski, J.; Golisz, E. The Agricultural Biogas Sector in Poland as Compared to Other European Union Member-Countries. Problemy światowego rolnictwa 2013, 13, 203-212.

3. KOWR, Rejestr wytwórców Biogazu Rolniczego, Stan na dzień 29.12.2020r. Available online: https://www.kowr.gov.pl/ odnawialne-zrodla-energii/biogaz-rolniczy/wytworcy-biogazu-rolniczego/rejestr-wytworcow-biogazu-rolniczego (accessed on 24 May 2021).

4. Voytovych, I.; Malovanyy, M.; Zhuk, V.; Mukha, O. Facilities and problems of processing organic wastes by familytype biogas plants in Ukraine. J. Water Land Dev. 2020, 45, 185-189. [CrossRef]

5. Myczko, A.; Sawiński, R.; Wrzesińska-Jędrusiak, E.; Aleszczyk, Ł.; Łaska-Zieja, B. Prosumer biogas installations for the sanitation of slurry and post-production residues from agricultural. Woda-Sr. i Obsz. Wiej. 2019, 19, 1.

6. Biernat, K.; Samson-Bręk, I. Review of technology for cleaning biogas to natural gas quality. Chemik 2011, 65, 435-444.

7. Holewa, J.; Kukulska-Zając, E.; Peggielska, M. Analysis of biogas injection into the gas transmission network. Nafta-Gaz 2012, 68, 523-529.

8. Golec, T.; Blesznowski, M. Hydrogen Economy-Perspectives of Origination and Development. Energetyka 2009, s.18. Available online: www.cire.pl/pliki/2/mozliwgoswodor.pdf (accessed on 27 May 2021).

9. Kothari, R.; Buddhi, R.; Sawhney, R.L. Comparoson of enwironmental and economic aspects of various hydrogen production methods. Renew. Sustain. Energy Rev. 2008, 12, 553-563. [CrossRef]

10. CCC. Hydrogen in a Low-Carbon Economy Committee on Climate Change. November 2018, pp. 1-128. Available online: www.theccc.org.uk/publications (accessed on 30 May 2021).

11. Fuel Cells and Hydrogen Joint Undertaking; Hydrogen Europe. Hydrogen Transport \& Distribution. 2019. Available online: https://hydrogeneurope.eu/hydrogen-transport-distribution (accessed on 1 June 2021).

12. Bossel, U. Well-to-Wheel Studies, Heating Values, and the Energy Conservation Principle. Proceedings of the European Fuel Cell Forum. 2003, pp. 1-5. Available online: http://www.ppwpp.org/customers/109022312245076/filemanager/Well_to_Wheel_ Studies_Heating_Values_and_the_Energy_Conserva.pdf (accessed on 13 May 2021).

13. Wiacek, D. Hydrogen as a fuel of the future. Autobusy 2011, 10, 446-452.

14. Chauhan, N.S.; Singh, V. Fundamentals and Use of Hydrogen as a Fuel. J. Mech. Eng. 2015, 6, 63-68. [CrossRef]

15. Van den Berg, A.W.C.; Arean, C.O. Materials for hydrogen storage: Current research trends and perspectives. Chem. Commun. 2008, 6, 668-681. [CrossRef] [PubMed] 
16. Porpatham, E.; Ramesh, A.; Nagalingam, B. Effect of hydrogen addition on the performance of a biogas fuelled spark ignition engine. Int. J. Hydrog. Energy 2007, 32, 2057-2065. [CrossRef]

17. Gómez-Montoya, J.P.; Cacua-Madero, K.P.; Iral-Galeano, L.; Amell-Arrieta, A.A. Effect of biogas enriched with hydrogen on the operation and performance of a diesel-biogas dual engine. CTyF-Cienc. Tecnol. y Futuro 2013, 5, 61-72. [CrossRef]

18. Jaworski, J.; Kukulska-Zając, E.; Kułaga, P. Selected issues concerning the impact of hydrogen addition to natural gas on the gas network components. Nafta-Gaz 2019, 10, 625-632. [CrossRef]

19. Myczko, A.; Myczko, R.; Kołodziejczyk, T.; Golimowska, R.; Lenarczyk, J. Budowa i Eksploatacja Biogazowni Rolniczych. Wydawnictwo ITP, Warszawa-Poznań. 2011. Available online: https://www.itp.edu.pl/old/wydawnictwo/indexbf07.html?id= budowa\&a=inne (accessed on 25 April 2021).

20. Dawid, L. Current status and perspectives on offshore wind farms development in the United Kingdom. J. Water Land Dev. 2019, 43, 49-55. [CrossRef]

21. DOE. DOE Hydrogen and Fuel Cells Program: Hydrogen Storage. U.S. Dep. Energy 2009, 25, 6. Available online: http: //www.hydrogen.energy.gov/storage.html (accessed on 15 May 2021). 